\title{
Metabotropic Glutamate Receptor 5 Modulates Nociceptive Plasticity via Extracellular Signal-Regulated Kinase-Kv4.2 Signaling in Spinal Cord Dorsal Horn Neurons
}

\author{
Hui-Juan Hu, Benedict J. Alter, Yarimar Carrasquillo, Chang-Sheng Qiu, and Robert W. Gereau IV \\ Washington University Pain Center and Department of Anesthesiology, Washington University School of Medicine, St. Louis, Missouri 63110
}

\begin{abstract}
Metabotropic glutamate receptors (mGluRs) play important roles in the modulation of nociception. The group I mGluRs (mGlu1 and mGlu5) modulate nociceptive plasticity via activation of extracellular signal-regulated kinase (ERK) signaling. We reported recently that the $\mathrm{K}^{+}$channel Kv4.2 subunit underlies A-type $\mathrm{K}^{+}$currents in the spinal cord dorsal horn and is modulated by the ERK signaling pathway. Kv4.2-mediated A-type currents are important determinants of dorsal horn neuronal excitability and central sensitization that underlies hypersensitivity after tissue injury. In the present study, we demonstrate that ERK-mediated phosphorylation of Kv4.2 is downstream of mGlu5 activation in spinal cord dorsal horn neurons. Activation of group I mGluRs inhibited Kv4.2-mediated A-type $\mathrm{K}^{+}$ currents and increased neuronal excitability in dorsal horn neurons. These effects were mediated by activation of mGlu5, but not mGlu1, and were dependent on ERK activation. Analysis of Kv4.2 phosphorylation site mutants clearly identified S616 as the residue responsible for mGlu5-ERK-dependent modulation of A-type currents and excitability. Furthermore, nociceptive behavior induced by activation of spinal group I mGluRs was impaired in Kv4.2 knock-out mice, demonstrating that, in vivo, modulation of Kv4.2 is downstream of mGlu5 activation. Altogether, our results indicate that activation of mGlu5 leads to ERK-mediated phosphorylation and modulation of Kv4.2containing potassium channels in dorsal horn neurons. This modulation may contribute to nociceptive plasticity and central sensitization associated with chronic inflammatory pain conditions.
\end{abstract}

Key words: excitability; plasticity; Kv4.2; ERK; spinal cord; pain; nociception

\section{Introduction}

The spinal cord superficial dorsal horn is a vital relay and a key site of modulation for the transmission of pain sensation. Various types of plasticity have been observed in the spinal cord dorsal horn after peripheral tissue damage (Ji et al., 2003), and it is thought that these forms of plasticity may contribute to the pathophysiology of chronic pain states. The group I metabotropic glutamate receptors (mGluRs), mGlu1 and mGlu5, have been implicated as mediators of nociceptive plasticity (Fisher and Coderre, 1996a,b; Karim et al., 2001; Varney and Gereau, 2002). Intrathecal administration of mGlu1/5 antagonists attenuates hypersensitivity attributable to nerve damage, inflammation, or noxious visceral stimulation (Young et al., 1997; Chen et al., 2000; Karim et al., 2001; Fisher et al., 2002). Pharmacological activation of mGlu1/5 in the spinal cord induces spontaneous pain-related behaviors, causes hypersensitivity to thermal and mechanical stimuli in the absence of peripheral tissue damage,

Received Jan. 20, 2007; revised 0ct. 10, 2007; accepted 0ct. 17, 2007.

This work was supported by National Institutes of Health Grant NS48602 and the Paralyzed Veterans of America Spinal Cord Research Foundation (R.W.G.). We thank Dr. Farzana Karim for assistance and Dr. Tom Schwarz and Dr. Jeanne Nerbonne for providing the Kv4.2 knock-out mice.

Correspondence should be addressed to Dr. Robert W. Gereau IV, Washington University Pain Center, Department of Anesthesiology, Washington University School of Medicine, 660 South Euclid Avenue, Campus Box 8054, St. Louis, M0 63110. E-mail: gereaur@wustl.edu.

D0I:10.1523/JNEUROSCI.0269-07.2007

Copyright $\odot 2007$ Society for Neuroscience $\quad$ 0270-6474/07/2713181-11\$15.00/0 and enhances formalin-induced spontaneous nociceptive behavior and complete Freund's adjuvant-induced mechanical hypersensitivity (Fisher and Coderre, 1996a,b, 1998; Karim et al., 2001; Adwanikar et al., 2004). These studies demonstrate that activation of mGlu1/5 in the spinal cord is necessary for the development of hypersensitivity in models of pathological pain and is sufficient to cause nociceptive behaviors in the absence of peripheral tissue damage.

Despite these recent advances, little is known about the cellular mechanisms that underlie mGlu1/5-mediated nociceptive plasticity. Previous studies from our laboratory have demonstrated that activation of mGlu1/5 leads to the activation of the extracellular signal-regulated kinase (ERK) and that nociceptive behavior resulting from the activation of spinal mGlul/5 is ERK dependent (Karim et al., 2001; Adwanikar et al., 2004). In a separate line of investigation, we identified the $\mathrm{K}^{+}$channel subunit Kv4.2 as a downstream target of ERK. ERK phosphorylates Kv4.2, modulates $\mathrm{Kv} 4.2$-mediated A-type $\mathrm{K}^{+}$currents, and regulates neuronal excitability in dorsal horn neurons. Furthermore, genetic elimination of the Kv4.2 subunit reduces ERK-dependent nociceptive behavior, demonstrating that $\mathrm{Kv} 4.2$ is a functional downstream effector of ERK in the dorsal horn and that it is necessary for various forms of nociceptive sensitization (Hu et al., 2006).

These results demonstrate that group I mGluRs modulate nociceptive information in the spinal cord via ERK activation and 
that ERK activation modulates excitability and nociceptive behavior via modulation of Kv4.2-mediated A-type $\mathrm{K}^{+}$currents. However, because ERK is responsive to many cell-surface signals in the spinal cord and can have numerous downstream effectors (Ji and Woolf, 2001; Obata and Noguchi, 2004), it remains to be determined whether mGlu1/5-mediated activation of ERK in the dorsal horn leads to ERK-mediated phosphorylation of Kv4.2 and the subsequent modulation of excitability and nociceptive behavior or whether these two signaling events occur as independent phenomena. We addressed this question in the present study and show that ERK-mediated phosphorylation of Kv4.2 is indeed downstream of mGlu5 activation in spinal cord dorsal horn neurons. Our results provide insights into the cellular mechanisms that underlie group I mGluR modulation of nociception.

\section{Materials and Methods}

Animals. All experiments were done in accordance with the guidelines of the National Institutes of Health and The International Association for the Study of Pain and were approved by the Animal Care and Use Committee of Washington University School of Medicine. Male and female CD1, 129 SvEv, and FVB mice were used. CD1, FVB, and 129 SvEv mice were used for electrophysiology experiments, and FVB mice were used for behavioral experiments (for details, see below). Current densities and kinetics of A-type currents in neurons from $129 \mathrm{SvEv}, \mathrm{FVB}$, and CD1 mice were not significantly different from each other (data not shown). All experiments within each group were performed using only a single strain.

Cell culture and spinal cord slice preparation. Primary cultures of spinal cord superficial dorsal horn neurons were prepared from 4- to 6-d-old CD1, FVB, and 129SvEv wild-type or Kv4.2 knock-out $\left(K v 4.2^{-/-}\right)$mice as described previously ( $\mathrm{Hu}$ et al., 2003). Briefly, after decapitation, a laminectomy was performed and the spinal cord was carefully removed. The superficial dorsal horn was dissected with a surgical blade cut in approximately lamina III. The superficial dorsal horn strips were incubated for $35 \mathrm{~min}$ at $37^{\circ} \mathrm{C}$ in HBSS (Invitrogen, Carlsbad, CA) (in mm: 137 $\mathrm{NaCl}, 5.4 \mathrm{KCl}, 0.4 \mathrm{KH}_{2} \mathrm{PO}_{4}, 1 \mathrm{CaCl}_{2}, 0.5 \mathrm{MgCl}_{2}, 0.4 \mathrm{MgSO}_{4}, 4.2$ $\mathrm{NaHCO}_{3}, 0.3 \mathrm{Na}_{2} \mathrm{HPO}_{4}$, and 5.6 glucose) containing papain $(15 \mathrm{U} / \mathrm{ml}$; Worthington Biochemical, Lakewood, NJ), rinsed three times with HBSS, and placed in culture medium containing Neurobasal (Invitrogen), fetal calf serum (2.5\%; Invitrogen), heat-inactivated horse serum (2.5\%; Invitrogen), L-glutamax-1 (2 mm; Invitrogen), and B-27 (2\%; Invitrogen). The strips were mechanically dissociated by gently triturating with a fire-polished Pasteur pipette. The resulting cell suspension was plated onto $12 \mathrm{~mm}$ poly-D-lysine- and collagen-coated coverslips and was cultured in humidified air with $5 \% \mathrm{CO}_{2}$ at $37^{\circ} \mathrm{C}$ for $1-2 \mathrm{~d}$ for voltageclamp recordings, for $6-8 \mathrm{~d}$ for current-clamp recordings, or for $4 \mathrm{~d}$ for immunocytochemistry. Lumbar spinal cord slices $(300-350 \mu \mathrm{m})$ were prepared from 6- to 10 -d-old CD1 or 129SvEv wild-type or $K v 4.2^{-/-}$ mice as described previously (Takahashi and Berger, 1990). Briefly, after decapitation, the vertebral column and surrounding tissue was isolated and immersed in ice-cold oxygenated artificial CSF (ACSF) containing the following (in mM): $118 \mathrm{NaCl}, 3 \mathrm{KCl}, 24 \mathrm{NaHCO}_{3}, 2 \mathrm{MgCl}_{2}, 1.25$ $\mathrm{NaH}_{2} \mathrm{PO}_{4}, 1 \mathrm{CaCl}_{2}$, and 12 glucose. The lumbar enlargement of the spinal cord was removed, glued down onto the cutting platform with the adhesive loctite 404 (Loctite, Rocky Hill, CT), and cut with a Vibratome 1000 (Vibratome, St. Louis, MO). Slices were maintained in ACSF at room temperature under continuous oxygenation and were allowed to recover for $1 \mathrm{~h}$ before electrophysiological recording.

Transfection of dorsal horn neurons. Spinal cord dorsal horn neurons were cultured for $24 \mathrm{~h}$ and then transfected with plasmid DNA constructs (0.45-0.9 $\mu \mathrm{g} /$ well) overnight using LipofectAMINE 2000 reagent according to the protocol of the manufacturer (Invitrogen). Patch-clamp recordings were performed $16-48 \mathrm{~h}$ after transfection. Kv4.2 point mutations in ERK phosphorylation sites were generated as described previously (Hu et al., 2006).

Electrophysiological recording. Standard whole-cell recordings were made at room temperature using either an Axopatch 200B amplifier and Clampex 8.0 software (Molecular Devices, Palo Alto, CA) or an EPC-10 amplifier and Pulse version 8.62 software (HEKA Elektronik, Lambrecht, Germany) as described previously (Hu and Gereau, 2003; Hu et al., 2003). Electrode resistances were $3-6 \mathrm{M} \Omega$ with series resistances of $6-15$ $\mathrm{M} \Omega$, which were compensated $>60 \%$. Resting membrane potentials were $-64.7 \pm 0.9 \mathrm{mV}(n=64)$ for neurons from slices and $-56.4 \pm 0.7$ $\mathrm{mV}(n=58)$ for cultured neurons, and only neurons with a resting membrane potential more hyperpolarized than $-50 \mathrm{mV}$ were used. All neurons had leak currents $<100 \mathrm{pA}$ (at $-80 \mathrm{mV}$ ), which were not subtracted on-line. Access resistance and input resistance were monitored by hyperpolarizing current injection throughout the course of the experiment. The data were rejected if either of these parameters changed $>20 \%$.

For voltage-clamp recordings in cultured neurons, the bath solution was HBSS containing $500 \mathrm{~nm}$ TTX and $2 \mathrm{~mm} \mathrm{CoCl}_{2}$ to block voltagegated $\mathrm{Na}^{+}$currents and $\mathrm{Ca}^{2+}$ currents. The electrode solution contained the following (in mM): $140 \mathrm{KCl}, 1 \mathrm{MgCl}_{2}, 0.5 \mathrm{CaCl}_{2}, 5 \mathrm{EGTA}, 10 \mathrm{HEPES}$, $3 \mathrm{Na}_{2} \mathrm{ATP}$, and $0.3 \mathrm{Na}_{2} \mathrm{GTP}, \mathrm{pH}$ 7.4. The membrane voltage was held at $-80 \mathrm{mV}$, and transient potassium currents $\left(I_{\mathrm{A}}\right)$ were isolated by a twostep voltage protocol as described previously (Hu et al., 2003). To determine the voltage dependence of activation, voltage steps of $500 \mathrm{~ms}$ were applied at $5 \mathrm{~s}$ intervals in $+10 \mathrm{mV}$ increments from $-80 \mathrm{mV}$ to a maximum of $+70 \mathrm{mV}$. To determine the voltage dependence of inactivation, conditioning prepulses ranging from -100 to $+40 \mathrm{mV}$ were applied in $+10 \mathrm{mV}$ increments for $150 \mathrm{~ms}$, followed by a step to $+40 \mathrm{mV}$ for 500 $\mathrm{ms}$. For current-clamp recording, the intracellular solution contained the following (in mM): $140 \mathrm{KMeSO}_{4}, 2 \mathrm{MgCl}_{2}, 1$ EGTA, $10 \mathrm{HEPES}, 3$ $\mathrm{Na}_{2} \mathrm{ATP}$, and $0.3 \mathrm{Na}_{2} \mathrm{GTP}, \mathrm{pH}$ 7.4. The bath solution for slices was ACSF bubbled with $95 \% \mathrm{O}_{2}-5 \% \mathrm{CO}_{2}$ and for cultures was HBSS. Action potentials were generated by current injection from a holding potential of $-70 \mathrm{mV}$ for cultured neurons and $-75 \mathrm{mV}$ for neurons from spinal cord slices. Throughout the recording, the holding potential was maintained by current injection. Intrinsic excitability was measured every $15 \mathrm{~s}$ using a constant amplitude small depolarizing pulse ( $800 \mathrm{~ms}, 10-80 \mathrm{pA})$. The amplitude that evoked two to eight action potentials during the baseline period was selected and remained constant throughout the recording. The first spike latency was measured as the time between the stimulus onset and the first spike of the response. The spike frequency was measured by counting the number of spikes within a depolarizing pulse of $800 \mathrm{~ms}$.

Western blot analysis. Six- to 7-week-old wild-type 129 SvEv or $K v 4.2^{-/-}$mice were decapitated, and the spinal cords were removed quickly by hydraulic extrusion with saline. The lumbar section of the spinal cord was dissected and homogenized using a dounce homogenizer in ice-cold homogenization buffer (HB) (20 mM Tris, $\mathrm{pH} 7.5,1$ mM EDTA, $1 \mathrm{mM} \mathrm{Na}_{4} \mathrm{P}_{2} \mathrm{O}_{7}, 25 \mu \mathrm{g} / \mathrm{ml}$ aprotinin, $25 \mu \mathrm{g} / \mathrm{ml}$ leupeptin, $0.2 \mathrm{mg} / \mathrm{ml} \mathrm{Na}_{3} \mathrm{VO}_{4}$, and $0.4 \mathrm{~mm}$ PMSF). Homogenates were centrifuged at $4^{\circ} \mathrm{C}$ for $5 \mathrm{~min}$ at $3000 \times \mathrm{g}$, and then the supernatants were spun at $4^{\circ} \mathrm{C}$ for $20 \mathrm{~min}$ at $60,000 \times g$ in a TLA 100.2 rotor. The precipitates from the $60,000 \mathrm{rpm}$ spin were resuspended in $\mathrm{HB}$ and were used for membrane protein analysis (mGlu5 and Kv4.2 assays). The precipitates from the $3000 \mathrm{rpm}$ spin were resuspended in the supernatant from the 60,000 rpm spin and were used for cytosolic and nuclear protein analysis (ERK assays). All samples were sonicated at a constant intensity of 2.5 for $10 \mathrm{~s}$. Protein concentrations were determined by the BCA assay kit (Pierce, Rockford, IL). Proteins were heated at $95^{\circ} \mathrm{C}$ for $3 \mathrm{~min}$ (for ERK assay), $60^{\circ} \mathrm{C}$ for $5 \mathrm{~min}$ (for mGlu 5 assay), or $60^{\circ} \mathrm{C}$ for $10 \mathrm{~min}$ (for $\mathrm{Kv} 4.2$ assay) and were electrophoresed (10 $\mu \mathrm{g}$ of protein) in 10\% (for total Kv4.2 and total ERK assays) or $8 \%$ (for mGlu5 assay) SDS polyacrylamide gels and transferred onto nitrocellulose membranes (blots). The blots were blocked with 5\% milk (for mGlu5 and Kv4.2 assays) or 3\% bovine serum albumin (for ERK assay) for $1 \mathrm{~h}$ at room temperature and then incubated for $1 \mathrm{~h}$ at room temperature with anti-Kv4.2 (1:500 in 5\% milk; Chemicon, Temecula, CA), anti-mGlu5 (1:1000 in 5\% milk; Upstate Biotechnology, Lake Placid, NY), or anti-ERK (1:2500 in 3\% BSA; Cell Signaling Technology, Beverly, MA) primary antibody. The blots were washed and incubated for $1 \mathrm{~h}$ at room temperature with HRP-conjugated 
secondary antibody (1:20,000 in blocking solution; Cell Signaling Technology). The blots were developed with SuperSignal West Pico (for mGlu5 and ERK assays) (Pierce) or SuperSignal West Femto (for Kv4.2 assay) (Pierce) and exposed onto hyperfilms. Densitometry of bands corresponding to ERK1 (p44), ERK2 (p42), and mGlu5 was performed using NIH ImageJ software.

Immunofluorescence. FVB wild-type and $\mathrm{Kv} 4.2^{-/-}$mice were anesthetized intraperitoneally with sodium pentobarbital $(60 \mathrm{mg} / \mathrm{kg})$ and perfused transcardially with $4 \%$ paraformaldehyde/phosphate buffer (PB) solution. Lumbar spinal cords were dissected out and postfixed overnight in $4 \%$ paraformaldehyde $/ \mathrm{PB}$ at $4^{\circ} \mathrm{C}$, followed by cryoprotection in $30 \%$ sucrose $/ \mathrm{PB}$ at $4^{\circ} \mathrm{C}$. Coronal sections $(30 \mu \mathrm{m})$ were cut with a cryostat (Leica, Nussloch, Germany) and were washed several times in $0.1 \mathrm{M}$ PBS. All incubations and washes were performed at room temperature unless otherwise noted. Sections were then blocked in 3\% normal goat serum (Vector Laboratories, Burlingame, CA) and 0.3\% Triton X-100 in $0.1 \mathrm{~m}$ PBS (3\% NGST) for $1 \mathrm{~h}$. All primary antibodies were diluted in 3\% NGST. Sections were incubated in a mixture of rabbit polyclonal antimGlu5 (1:1600; Upstate Biotechnology) and mouse monoclonal anti$\mathrm{Kv} 4.2$ antibody (1:100; Antibodies Incorporated, Davis, CA) at $4^{\circ} \mathrm{C}$ overnight. Sections were rinsed with 3\% NGST three times for 10 min each and were blocked in $10 \%$ NGST ( $10 \%$ normal goat serum, $0.3 \%$ Triton $\mathrm{X}-100$ in $0.1 \mathrm{M} \mathrm{PBS}$ ) for $1 \mathrm{~h}$, followed by incubation in a mixture of secondary goat anti-rabbit cyanine 5 (Cy5)-conjugated antibody (1:1000; Zymed Laboratories, South San Francisco, CA) and goat antimouse Cy3-conjugated antibody (1:1000; Zymed Laboratories) in 10\% NGST. The sections were rinsed in PBS and observed under a confocal laser-scanning microscope (Olympus Optical, Tokyo, Japan).

Cultured spinal cord neurons were fixed with $2 \%$ paraformaldehyde for $5 \mathrm{~min}$ and further fixed with $4 \%$ paraformaldehyde for $10 \mathrm{~min}$ at $4^{\circ} \mathrm{C}$. Cells were rinsed with $0.1 \mathrm{M}$ PBS four times for $5 \mathrm{~min}$ each and then stained by the same procedure used for spinal cord sections except that $0.02 \%$ Triton X-100 was used. For double staining of mGlu5 and Kv4.2 subunit, cells were incubated in a mixture of rabbit polyclonal antimGlu5 (1:1600; Upstate Biotechnology) and mouse monoclonal antiKv4.2 (1:200; Antibodies Incorporated) primary antibodies and then Cy3- and Cy5-conjugated secondary antibodies (1:1000). For double staining of phosphorylated (p)-ERK and Kv4.2 subunit, cells were incubated in a mixture of polyclonal anti-pERK (1:100; Cell Signaling Technology) and mouse monoclonal anti-Kv4.2 antibody (1:200; Antibodies Incorporated) and then in a mixture of secondary anti-rabbit Alexa-488conjugated IgG (1:2000; Invitrogen) and anti-mouse Cy3-conjugated antibody (1:1000) at room temperature. The intensity of pERK immunostaining was quantified using Olympus Optical Fluoview software. All the quantification was performed blind to experimental conditions. All Kv4.2-positive cells were selected, and the average intensity of pERK in the selected cell was measured. All values were normalized to the mean of the average intensity in the vehicle-treated group.

Behavioral studies. Behavioral testing was performed with the investigator blind to genotype using 7 - to 9-week-old FVB wild-type ( 11 male and seven female mice) and $K v 4.2^{-1-}$ littermates (seven male and six female mice). Mice on the FVB background were used for these experiments because mice on the 129 SvEv background did not exhibit the stereotypical $(R, S)$-3,5-dihydroxyphenylglycine (DHPG)-induced spontaneous nociceptive behavior. Data from male and female mice were pooled because there was no significant sex difference ( $p>0.05$, data not shown). Animals were placed in clean plastic mouse housing cages for $1-2 \mathrm{~h}$ before beginning an experiment. DHPG-induced nociceptive behavior was elicited by intrathecal injection of DHPG $(6 \mathrm{nmol})$ and assayed by recording the total time spent in spontaneous nociceptive behavior (caudally oriented licking of the flanks, tail, and hindpaw) in 5 min intervals for $15 \mathrm{~min}$ as described previously (Karim et al., 2001).

Drug application. U0126 [bis[amino[(2-aminophenyl)thio]methylene]butanedinitrile] (Biomol, Plymouth Meeting, PA) and PD98059 [2-(2-amino-3-methyoxyphenyl)-4 H-1-benzopyran-4-one] (Sigma-Aldrich, St. Louis, MO) were prepared as concentrated stock solutions in DMSO and diluted to final concentrations in HBSS or ACSF for bath applications. DHPG, LY367385 [(+)-2-methyl-4-carboxy- phenylglycine], and 2-methyl-6-(phenylethynyl)-pyridine (MPEP) were purchased from Tocris Biosciences (Ballwin, MO). DHPG was dissolved in HBSS or ACSF for bath application or in PBS for intrathecal injections. LY367385 and MPEP were first dissolved in $0.1 \mathrm{~N} \mathrm{NaOH}$ and DMSO, respectively, as stock solutions and then diluted to the final concentration in HBSS. For electrophysiology experiments, DHPG was applied for $3 \mathrm{~min}$. For inhibitor or antagonist experiments, neurons were pretreated with antagonists (LY367385 or MPEP) for 3 min or inhibitors (PD98059 or U0126) for $5 \mathrm{~min}$, and then DHPG was coapplied with the antagonist or inhibitor for 3 additional minutes. Drug concentrations were used as described previously: $500 \mathrm{~nm}$ U0126, $20 \mu \mathrm{M}$ PD98059 (Hu and Gereau, 2003; Hu et al., 2003); $100 \mu \mathrm{M}$ DHPG, $50 \mu \mathrm{M}$ LY367385, and $5 \mu \mathrm{M}$ MPEP (Mannaioni et al., 2001; Hu et al., 2002; Topolnik et al., 2006).

Data analysis. Off-line evaluation was done using Clampfit 8.0 software (Molecular Devices) and Origin (Microcal Software, Northampton, MA). Data are expressed as original traces or as mean \pm SEM. The voltage dependence of activation and inactivation of $I_{\mathrm{A}}$ was fitted with the Boltzmann function. For activation, peak currents were converted to conductances $(G)$ by the formula $G=I /\left(V_{\mathrm{m}}-V_{\text {rev }}\right)$, where $V_{\mathrm{m}}$ is the membrane voltage of depolarization pulses, and $V_{\text {rev }}$ is the calculated potassium reversal potential $(-84 \mathrm{mV})$. The function $G / G_{\max }=1 /(1+$ $\exp \left[\left(V_{1 / 2}-V\right) / k\right]$ was used to normalize conductances, where $G_{\max }$ is the maximal conductance obtained with a depolarizing pulse to $+70 \mathrm{mV}$, $V_{1 / 2}$ is the half-maximal voltage, and $k$ is the slope factor. For inactivation, $I / I_{\max }=1 /\left(1+\exp \left[\left(V_{1 / 2}-V\right) / k\right]\right.$ was used, where $I_{\max }$ is the maximal current obtained with a $-100 \mathrm{mV}$ prepulse.

For all experiments, treatment effects were statistically analyzed by one-way ANOVA, followed by the appropriate post hoc tests using Statistica software. Paired or two-sample Student's $t$ test was used when comparisons were restricted to two means. Error probabilities of $p<0.05$ were considered statistically significant.

\section{Results}

\section{Activation of group I mGluRs increases excitability in dorsal} horn neurons

Previous studies have demonstrated that activation of spinal mGlu1/5 causes nociceptive behaviors, which are ERK dependent (Adwanikar et al., 2004). At the cellular level, ERK has been shown to be an important modulator of neuronal excitability (Yuan et al., 2002; Hu and Gereau, 2003; Kawasaki et al., 2004; Sluka and Audette, 2006). Because mGlu1 and mGlu5 have been shown to be upstream activators of ERK in the dorsal horn ( $\mathrm{Ka}$ rim et al., 2001), it is reasonable to hypothesize that activation of mGlu1/5 also modulates neuronal excitability in superficial dorsal horn neurons of the spinal cord. To test this hypothesis, we performed whole-cell current-clamp recordings and investigated the effects of DHPG, a group I mGluR agonist, on action potentials evoked by current injection in spinal cord dorsal horn neurons in culture and in acute slices from CD1 mice. In slices, application of $100 \mu \mathrm{M}$ DHPG decreased first spike latency by $35.1 \pm 5.3 \%$ and increased spike frequency by $45.5 \pm 13.4 \%$ (Fig. $1 A-C)$. DHPG had similar effects on action potentials in cultured neurons (Fig. $1 A-C$ ). These results are consistent with our hypothesis that activation of group I mGluRs modulates neuronal excitability in the spinal cord dorsal horn.

\section{Activation of group I mGluRs decreases A-type currents in dorsal horn neurons}

We have shown previously that downregulation of A-type currents enhances neuronal excitability in dorsal horn neurons $(\mathrm{Hu}$ and Gereau, 2003; Hu et al., 2003). We hypothesized that the mechanism of mGlu1/5-induced increases in neuronal excitability is via downregulation of A-type currents. To test this hypothesis, we performed whole-cell voltage-clamp recordings on cultured spinal dorsal horn neurons from CD1 mice. A large outward current was evoked by a depolarizing step to $+40 \mathrm{mV}$ 
from a holding potential of $-80 \mathrm{mV}$. The A-type current was dissected away from the sustained potassium current by a twostep voltage protocol as described previously (Hu et al., 2003). We bath applied DHPG $(100 \mu \mathrm{M})$ and measured changes in the peak amplitude of A-type and delayed rectifier $\mathrm{K}^{+}$currents. DHPG at $100 \mu \mathrm{M}$ caused a reversible decrease in the peak of A-type current by $21.0 \pm 1.6 \%$ (Fig. $1 D-E)$ but had no significant effect on delayed rectifier currents (decreased by $3.2 \pm$ $1.3 \%$ with DHPG and $1.0 \pm 1.7 \%$ with vehicle; $n=9-21 ; p>0.05)$. We also examined A-type current decay kinetics at a depolarizing step of $+40 \mathrm{mV}$. The decay phase of A-type currents could be fit with a double-exponential function with time constants $\tau_{\text {fast }}$ of $17 \pm 2 \mathrm{~ms}$ and $\tau_{\text {slow }}$ of $346 \pm 40 \mathrm{~ms}(n=12)$. The rates of inactivation of A-type currents were not altered by DHPG application ( $\tau_{\text {fast }}$ of $16 \pm 2 \mathrm{~ms}$ and $\tau_{\text {slow }}$ of $347 \pm 38 \mathrm{~ms} ; n=12$ ). Steadystate inactivation and activation curves generated from these experiments show a significant shift of the activation curve $V_{1 / 2}$ to the right $7.3 \mathrm{mV}$ and a shift of the inactivation curve $V_{1 / 2}$ to the left $7.2 \mathrm{mV}$ in response to $100 \mu \mathrm{M}$ DHPG (Fig. $1 F$, Table 1 ). The slope factor of the activation curve was also significantly changed, but the slope of the inactivation curve remained the same (Table 1). These nonparallel shifts in the activation and inactivation curves likely reflect heterogeneity in the population of channels mediating the A-type currents in these neurons.

\section{Kv4.2 is required for mGlu1/5 modulation of A-type currents and neuronal excitability in dorsal horn neurons}

In a previous study, we demonstrated that A-type currents in dorsal horn neurons are mainly mediated by subunits from the Kv4 family (Hu et al., 2006). Accordingly, A-type currents in cultured dorsal horn neurons from 129 SvEv Kv4.2 $2^{-/-}$mice were decreased by $60 \%$ when compared with wild-type cultures from the same strain (note that A-type currents in the 129SvEv neurons were similar to those in CD1 neurons) ( $\mathrm{Hu}$ et al., 2006). For this reason, we hypothesized that DHPG modulation of A-type currents and excitability are also mediated by the Kv4.2 subunit. To test this hypothesis, we evaluated the effects of DHPG on A-type currents and excitability in Kv4.2 $2^{-/-}$neurons. Consistent with the experiments described above, bath application of $100 \mu \mathrm{M}$ DHPG decreased A-type currents by $20.0 \pm 3.3 \%$ in dorsal horn neurons from wildtype mice; however, we found that DHPG had no significant effect on A-type currents in dorsal horn neurons from Kv4.2 knock-out mice (Fig. $2 A, B$ ). In current-clamp recordings from mouse spinal cord slices, DHPG decreased first spike latency and increased spike frequency in wild-type dorsal horn neurons but had no significant effects on the firing properties of $K v 4.2^{-1-}$ neurons (Fig. $2 C, D$ ). These results demonstrate that Kv4.2 expression is necessary for DHPG-induced modulation of A-type currents and neuronal excitability in mouse dorsal horn neurons.
B.

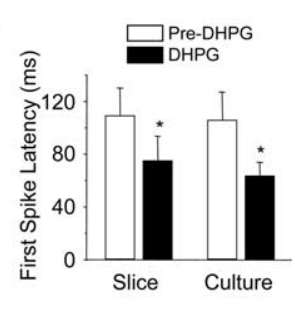

C.

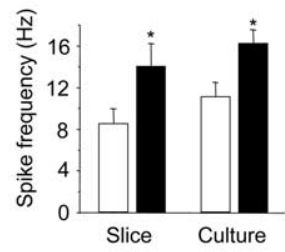

F.
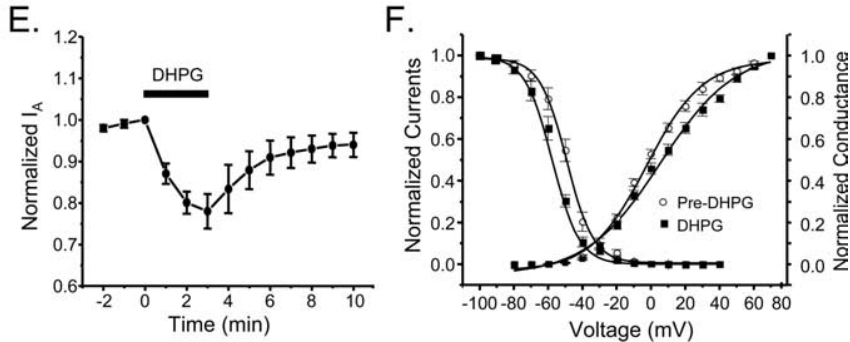

Figure 1. Group I mGluR activation increases excitability and decreases A-type currents in dorsal horn neurons. $A$, Represen-

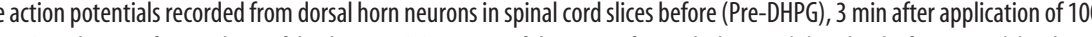
mean \pm SEM; $n=8-10$ neurons each.

ERK is required for mGlu1/5 modulation of A-type currents and neuronal excitability in dorsal horn neurons

As demonstrated above, activation of group I mGluRs decreases A-type currents and increases neuronal excitability in spinal dorsal horn neurons. We have shown previously that nociceptive behaviors induced by activation of spinal mGlu1/5 are ERK dependent and that the ERK signaling pathway is involved in modulation of A-type currents and excitability (Hu et al., 2003, 2006; Adwanikar et al., 2004). Therefore, we hypothesized that modulation of A-type currents and excitability by group I mGluRs is via the ERK signaling pathway. To test this hypothesis, we first examined the effects of two mitogen-activated protein kinase kinase inhibitors, PD98059 and U0126, on DHPG-induced inhibition of A-type currents in dorsal horn neurons from CD1 mice. Pretreatment with $20 \mu \mathrm{M}$ PD98059 completely blocked DHPG-induced inhibition of A-type currents and prevented the DHPG-induced shift of the activation and inactivation curves (Fig. $3 A-C$, Table 1). Similar results were obtained with 500 nM U0126 (Fig. 3A,C). Both PD98059 and U0126 alone increased A-type currents as we reported previously (data not shown) (Hu et al., 2003). We then tested whether ERK signaling is necessary for DHPG-induced enhancement of neuronal excitability. Pretreatment with $20 \mu \mathrm{M}$ PD98059 completely blocked the effects of DHPG on first spike latency and spike frequency (Fig. 3D,E). Altogether, these results indicate that mGlul/5 activation modulates A-type currents and neuronal excitability through ERK signaling.

To confirm that DHPG induces activation of ERK in cultured dorsal horn neurons, we treated cells with $100 \mu \mathrm{M}$ DHPG for various lengths of time. Analysis of confocal immunofluorescence images revealed that DHPG increased pERK staining intensity when compared with vehicle-treated cells (Fig. 4). DHPG induced a time-dependent activation of ERK that peaked at the 5 min time point (Fig. 4).

To test whether DHPG activates ERK in Kv4.2-expressing neurons, we costained DHPG-treated dorsal horn neurons with anti-Kv4.2 and anti-pERK antibodies. A total of $556 \mathrm{Kv} 4.2-$ 
Table 1. Effects of DHPG in the presence of vehicle or PD98059 on the voltage dependence of A-type current activation and inactivation

\begin{tabular}{|c|c|c|c|c|c|c|}
\hline & \multicolumn{3}{|l|}{ Activation } & \multicolumn{3}{|l|}{ Inactivation } \\
\hline & $V_{1 / 2}$ & $k$ & $n$ & $V_{1 / 2}$ & $k$ & $n$ \\
\hline Pre-DHPG & $-2.2 \pm 1.2$ & $17.2 \pm 0.9$ & 10 & $-50.7 \pm 1.9$ & $7.2 \pm 0.6$ & 9 \\
\hline DHPG & $5.1 \pm 2.3^{*}$ & $22.5 \pm 1.3^{*}$ & 10 & $-57.9 \pm 2.1^{*}$ & $7.9 \pm 1.3$ & 9 \\
\hline PD treated & $-7.6 \pm 1.3$ & $19.2 \pm 1.2$ & 12 & $-46.8 \pm 2.2$ & $9.0 \pm 0.8$ & 11 \\
\hline$P D+D H P G$ & $-6.8 \pm 1.7$ & $19.4 \pm 1.5$ & 12 & $-49.0 \pm 4.6$ & $10.4 \pm 1.4$ & 11 \\
\hline MPEP treated & $-2.4 \pm 3.6$ & $19.5 \pm 1.2$ & 9 & $-56.9 \pm 1.9$ & $8.8 \pm 0.8$ & 9 \\
\hline MPEP + DHPG & $-4.2 \pm 3.7$ & $20.6 \pm 1.3$ & 9 & $-58.2 \pm 1.9$ & $9.3 \pm 1.0$ & 9 \\
\hline
\end{tabular}

${ }^{*} p<0.05$, paired $t$ test. PD, PD98059.

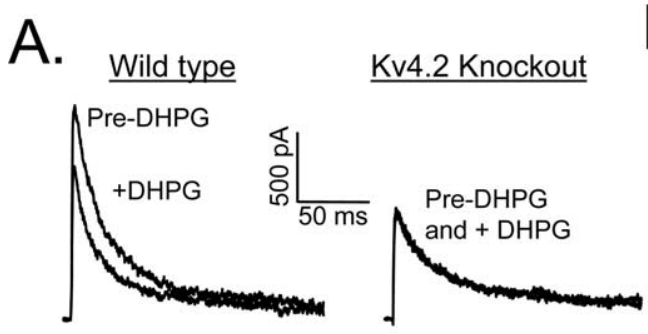

B.
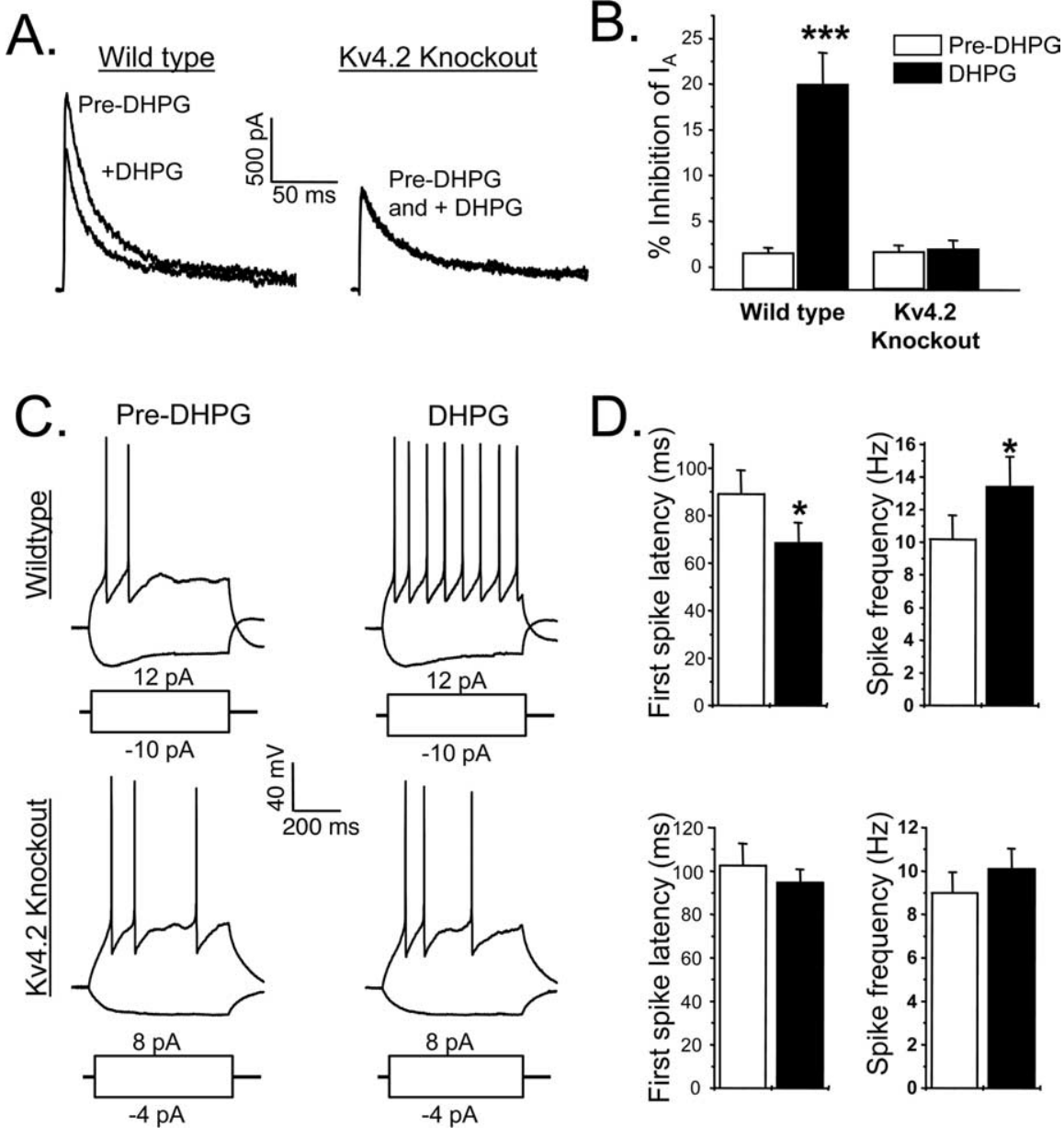

Figure 2. Kv4.2 is required for mGlu1/5-mediated modulation of A-type currents and neuronal excitability. $\boldsymbol{A}$, Representative traces of A-type currents recorded before (Pre-DHPG) and 3 min after application of $100 \mu \mathrm{m}$ DHPG to wild-type or $K v 4.2^{-/-}$dorsal horn neurons. B, Summary of the effects of DHPG on peak amplitude of A-type currents in wild-type or Kv4.2 $2^{-1-}$ neurons. Values represent mean \pm SEM; $n=7-10$ neurons each; ${ }^{* *} p<0.001$, two-sample Student's $t$ test. C, Representative action potentials recorded from lamina I-II dorsal horn neurons in spinal cord slices of wild-type or Kv4.2 $2^{-1-}$ mice before and 3 min after application of $100 \mu \mathrm{m}$ DHPG. D, Summary of changes in first spike latency and spike frequency induced by DHPG in dorsal horn neurons from wild-type or Kv4.2 $2^{-/-}$slices. Values represent mean \pm SEM; $n=6-11$ neurons each; ${ }^{*} p<0.05$, paired Student's $t$ test.

positive neurons from three different cultures were examined. All Kv4.2-positive neurons examined were also positive for pERK (Fig. 4A), whereas only 71\% (134 of 188) of the pERK-positive cells were also Kv4.2 positive.

\section{Phosphorylation site S616 mediates DHPG modulation of Kv4.2}

Previous studies using purified fusion proteins identified three sites that can be phosphorylated by ERK in the Kv4.2 intracellular domains in vitro (Adams et al., 2000). Of these three sites, only the

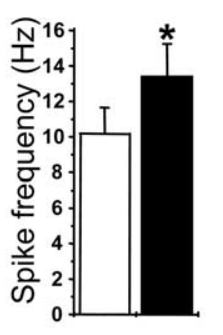

serine at residue number $616(\mathrm{~S} 616)$ is necessary for modulation of A-type currents by $\mathrm{PKC}$-mediated ERK activation in dorsal horn neurons (Hu et al., 2006). To identify which of these phosphorylation sites (if any) mediates modulation of A-type currents by DHPG-induced ERK activation, we transfected dorsal horn neurons from FVB $K v 4.2^{-/-}$mice, which show the same phenotype as 129SvEv Kv4.2 $2^{-/-}$mice, with either wild-type $\mathrm{Kv} 4.2$ or alanine point mutants of the putative ERK phosphorylation sites T602, T607, and S616 (Hu et al., 2006). Similar to our previous report, transfection of $K v 4.2^{-/-}$dorsal horn neurons with wildtype Kv4.2, T602A, or T607A restored A-type currents (Fig. 5). These currents were inhibited by $100 \mu \mathrm{M}$ DHPG, similar to what we observed in wild-type neurons (Fig. 5). A-type currents were also restored in $\mathrm{Kv} 4.2^{-1-}$ dorsal horn neurons transfected with the S616A mutant of Kv4.2, but DHPG-induced modulation of A-type currents was absent in these transfected neurons (Fig. 5).

DHPG-induced phosphorylation of S616 may diminish A-type currents by altering the voltage dependence of A-type current activation, inactivation, or both. To elucidate the effects of DHPG on these gating properties, we transfected $K v 4.2^{-/-}$ dorsal horn neurons with wild-type Kv4.2 or S616A constructs and evaluated the activation and inactivation of A-type currents before and after application of DHPG $(100 \mu \mathrm{M})$. In wild-type-transfected neurons, DHPG significantly shifted the inactivation curve to more hyperpolarized potentials without affecting the slope factor $\left(\right.$ pre-DHPG, $V_{1 / 2}=-46.0 \pm 3.0, k=$ $10.4 \pm 1.1 ; \mathrm{DHPG}, V_{1 / 2}=-53.6 \pm 3.0$, $k=10.4 \pm 0.8 ; p<0.05$ comparing $V_{1 / 2}$, paired $t$ test), which is consistent with results obtained with wild-type neurons endogenously expressing Kv4.2 (Fig. $1 F$ ). In wild-type-transfected neurons, DHPG significantly increased the slope factor of the activation curve (pre-DHPG, $k=16.7 \pm 0.7$; DHPG, $k=19.9 \pm 1.2$; $p<0.05$, paired $t$ test) without significantly shifting $V_{1 / 2}$ (preDHPG, $V_{1 / 2}=2.8 \pm 1.6$; DHPG, $V_{1 / 2}=5.3 \pm 2.1 ; p>0.05$, paired $t$ test). Although in transfected cells there was no statistically significant shift in the $V_{1 / 2}$ of the activation curve, these data 
trend toward a depolarizing shift, which is consistent with our observations from wild-type cells (Fig. 1F). Importantly, in S616A-transfected neurons, DHPG did not significantly affect either the activation (pre-DHPG, $V_{1 / 2}=8.9 \pm 2.5, k=19.9 \pm$ 2.0; DHPG, $V_{1 / 2}=7.1 \pm 2.5, k=19.5 \pm$ 1.0) or inactivation (pre-DHPG, $V_{1 / 2}=$ $-44.8 \pm 4.3, k=13.5 \pm 2.7$; DHPG, $V_{1 / 2}$ $=-47.9 \pm 3.9, k=13.3 \pm 2.4)$ curves, indicating that S616 is necessary for DHPG-induced modulation of activation and inactivation properties of A-type currents. Overall, these results indicate that S616 is the phosphorylation site that mediates DHPG-induced modulation of A-type currents via alteration of the voltage dependence of both activation and inactivation.

\section{mGlu5 mediates DHPG-induced modulation of A-type currents and neuronal excitability}

DHPG is a selective group I mGluR agonist that acts on both mGlu1 and mGlu5 receptor subtypes. To determine the contribution of each group I mGluR subtype to DHPG-induced modulation of A-type currents, we tested the effects of specific mGlu1 or mGlu5 antagonists on this modulation. First, we coapplied the mGlu1 antagonist LY367385 with DHPG $(100 \mu \mathrm{M})$ to isolate the specific contribution of mGlu5. In the presence of LY367385 (50 $\mu \mathrm{M})$, application of $100 \mu \mathrm{M}$ DHPG was still able to reduce peak A-type currents by $20.0 \pm 1.5 \%$ and increase excitability of spinal dorsal horn neurons (Fig. 6). However, pretreatment with $5 \mu \mathrm{M} \mathrm{MPEP}$, an mGlu5 antagonist, completely blocked DHPG-induced inhibition of A-type currents and prevented the DHPG-induced shift of the activation and inactivation curves (Table 1). In addition, DHPG had no significant effect on neuronal excitability in the presence of MPEP in cultured spinal dorsal horn neurons (Fig. 6). Neither LY367385 nor MPEP alone altered the A-type current amplitude (Fig. 6) or neuronal excitability (data not shown). These results indicate that mGlu5 is the predominant mGluR mediating DHPG-induced inhibition of A-type currents. Consistent with this finding, immunofluorescent staining of spinal cord slices revealed that mGlu 5 is colocalized with Kv4.2 in the superficial dorsal horn (Fig. 7A). We were not able to clearly distinguish individual neurons in the stained slices. Therefore, we performed double immunofluorescence staining for Kv4.2 and mGlu5 in dissociated dorsal horn neurons (Fig. 7B). A total of 208 neurons from four different cultures were examined; 197 of these neurons were Kv4.2 positive, and 181 neurons were mGlu5 positive. Kv4.2 and mGlu5 colocalized in $170(82 \%)$ of these neurons. Thus, $86 \%$ of Kv4.2-positive neurons were mGlu5 positive, and $94 \%$ of mGlu5-positive neurons were Kv4.2 positive. Kv4.2 was only expressed in neurons because all Kv4.2-positive cells were also neuronal-specific nuclear protein positive (data not shown). Kv4.2 immunostaining was spe-

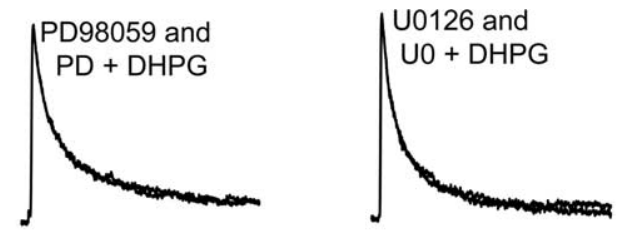

C.

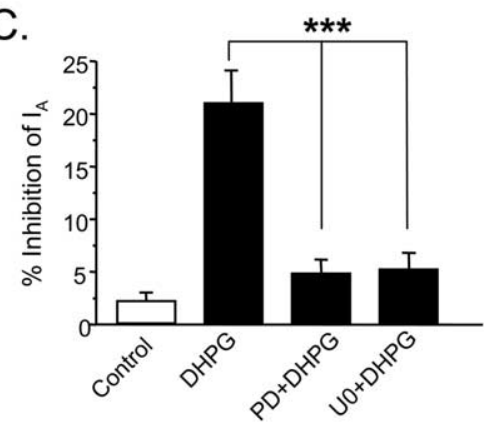

PD+DHPG E.
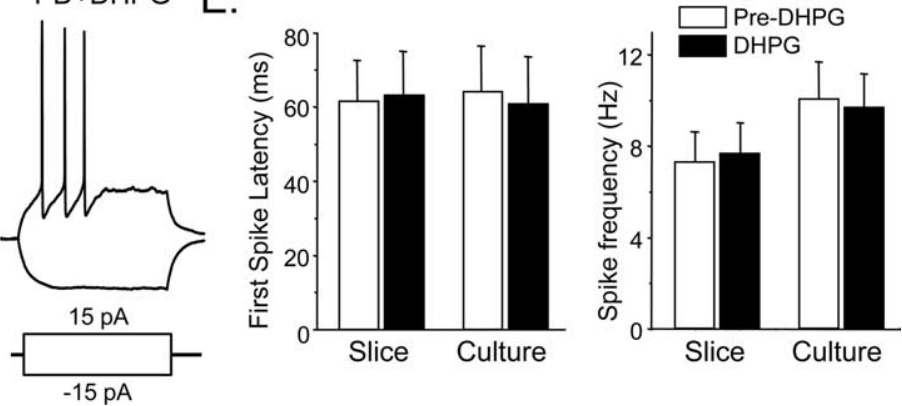

Figure 3. ERK activation is necessary for mGlu1/5-medited modulation of A-type currents and neuronal excitability. $\boldsymbol{A}$, Representative traces of A-type currents recorded before and after application of $100 \mu \mathrm{m}$ DHPG in the presence of vehicle, $20 \mu \mathrm{M}$ 作 $\mu \mathrm{M}$ DHPG in the presence of $20 \mu \mathrm{m}$ PD98059. E, Summary of changes in first spike latency and spike frequency induced by DHPG in dorsal horn neurons of slices and cultures in the presence of PD98059. Values represent mean \pm SEM; $n=8$ neurons each.

cific under our experimental conditions because it was not present in $K v 4.2^{-1-}$ mice (Fig. 7).

\section{DHPG-induced spontaneous nociceptive behavior is impaired in Kv4.2 knock-out mice}

Previous studies have demonstrated that activation of spinal group I mGluRs generates spontaneous nociceptive responses (Fisher and Coderre, 1998; Karim et al., 2001) and that this effect of DHPG is at least partially mediated by ERK activation (Adwanikar et al., 2004). The mechanisms underlying these responses are not clear. In the present study, we show that activation of group I mGluRs by DHPG modulates A-type currents and neuronal excitability in the spinal cord dorsal horn through ERKmediated phosphorylation of Kv4.2. Given that DHPG effects on cellular physiology are Kv4.2 dependent, it is reasonable to hypothesize that DHPG-induced nociceptive behavior will also be Kv4.2 dependent. To test this hypothesis, we gave a single intrathecal injection of $6 \mathrm{nmol}$ DHPG to FVB $K v 4.2^{-/-}$mice or wildtype littermates and recorded the time spent in nociceptive behaviors for $15 \mathrm{~min}$. Before DHPG administration, wild-type and $K v 4.2^{-/-}$mice exhibited no spontaneous nociceptive behavior. Consistent with previous reports (Fisher and Coderre, 1996b; Karim et al., 2001; Adwanikar et al., 2004), intrathecal injection 

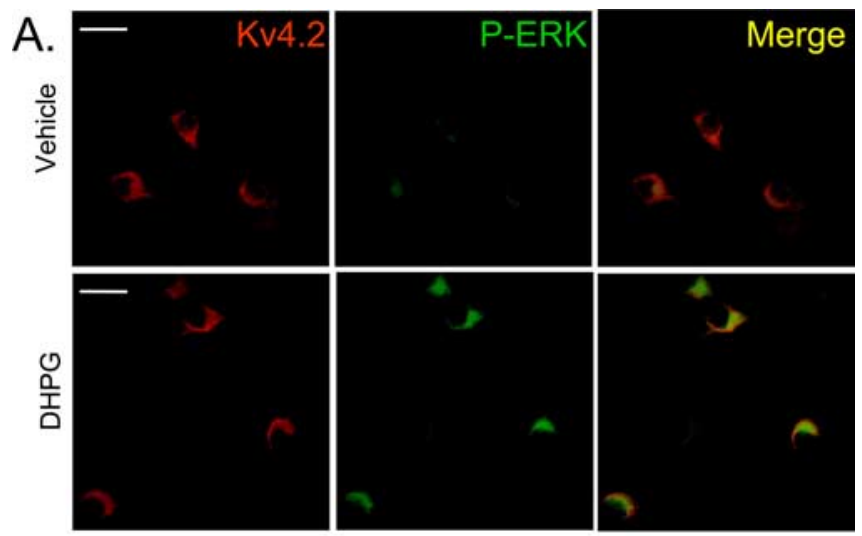

B.

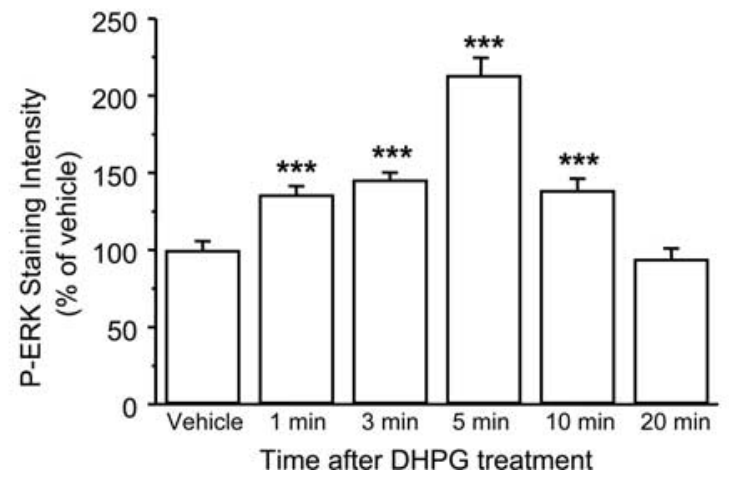

Figure 4. DHPG induces ERK activation in Kv4.2-expressing dorsal horn neurons. $\boldsymbol{A}$, Representative confocal images of Kv4.2 (red) and pERK (green) coimmunofluorescent staining in cultured dorsal horn neurons treated with vehicle or $100 \mu \mathrm{m}$ DHPG. Merge of Kv4.2 and pERK is shown in yellow. Scale bars, $40 \mu \mathrm{m}$. $\boldsymbol{B}$, Time course of DHPG-induced ERK phosphorylation. Intensity of $\mathrm{pERK}$ is expressed as percentage of vehicle. Values represent mean $\pm \mathrm{SEM} ; n=$ $140-207$ neurons from three different cultures; ${ }^{* * *} p<0.001$, one-way ANOVA followed by Dunnett's post hoc test to compare with vehicle group.

of DHPG induced robust spontaneous nociceptive responses that included caudally oriented licking of the flanks, hindpaws, and tail in wild-type mice (Fig. 8A). Conversely, DHPG-induced spontaneous nociceptive responses were significantly reduced 10 and $15 \mathrm{~min}$ after DHPG injection in $\mathrm{Kv} 4.2^{-/-}$mice relative to their wild-type littermates. These results demonstrate that Kv4.2 expression is necessary for DHPG-induced spontaneous nociceptive behavior.

To determine whether the lack of DHPG-induced modulation of Kv4.2 in the knock-out mice was attributable to altered expression of other proteins involved in the modulation of Kv4.2, we examined protein levels of total ERK and mGlu5 by immunoblotting using ERK- or mGlu5-selective primary antibodies. There was no significant difference in the amount of total ERK or mGlu5 in spinal cord homogenates taken from wild-type and Kv4.2 $2^{-/-}$mice (Fig. 8 B).

\section{Discussion}

Results from the present study reveal a functional link between mGlu5, ERK, and Kv4.2 at both cellular and behavioral levels. Activation of group I mGluRs dramatically affects the excitability of spinal cord dorsal horn neurons in an ERK-dependent manner. This effect on excitability is achieved by the modulation of A-type currents through the ERK signaling cascade. Moreover, we identified Kv4.2 as the subunit responsible for the portion of the A-type current that is modulated by group I mGluRs. Our point mutation experiments further demonstrated that modulation of Kv4.2 is mediated by direct phosphorylation of the chan-
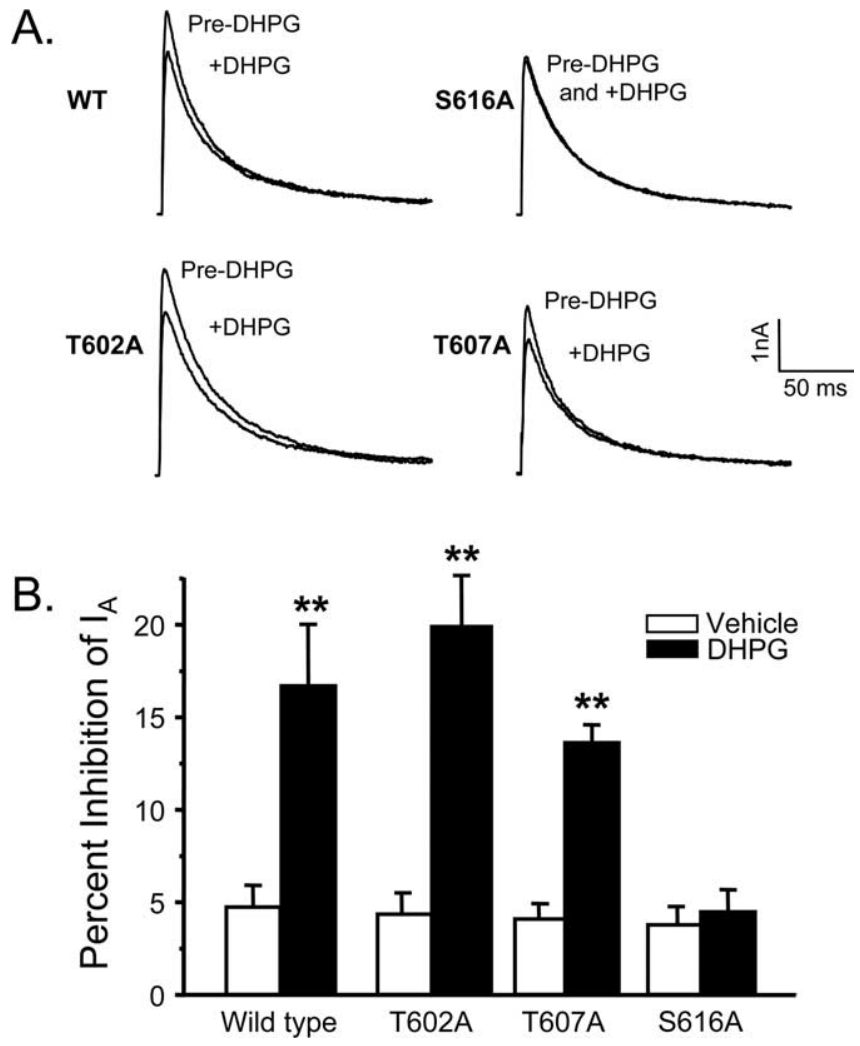

Figure 5. Phosphorylation of Kv4.2 by ERK at $\$ 616$ mediates mGlu5 modulation of A-type currents. $\boldsymbol{A}$, Representative traces of A-type currents recorded from $\mathrm{Kv} 4.2^{-1-}$ neurons transfected with enhanced green fluorescent protein (EGFP) plus wild-type (WT) Kv4.2 or EGFP plus Kv4.2 phosphorylation site mutants (T602A, T606A, or S616A) before (Pre-DHPG) and 3 min after application of $100 \mu \mathrm{m}$ DHPG. $\boldsymbol{B}$, Summary of the effects of DHPG on peak amplitude of A-type currents in Kv4.2 $2^{-/-}$neurons transfected with EGFP plus wild-type Kv4.2 or EGFP plus Kv4.2 phosphorylation site mutants. Values represent mean $\pm \mathrm{SEM} ; n=6-8$ neurons each; ${ }^{* *} p<0.01$, two-sample Student's $t$ test.

nel by ERK at the S616 phosphorylation site. These in vitro observations are borne out in vivo because we found that $\mathrm{Kv} 4.2$ is necessary for nociceptive behaviors elicited by the activation of spinal group I mGluRs.

In the present study, we identified group I mGluRs as novel upstream modulators of Kv4.2-mediated A-type currents in spinal dorsal horn neurons and demonstrate that this modulation affects changes in excitability. These results are consistent with the well known role of A-type potassium channels as important regulators of neuronal excitability (Shibata et al., 2000; Hu and Gereau, 2003; Jerng et al., 2004; Varga et al., 2004; Vydyanathan et al., 2005). These findings also fit well with a large body of data implicating a variety of G-protein-coupled receptors as modulators of A-type currents and neuronal excitability (Wang et al., 1997; Starodub and Wood, 2000; Burdakov and Ashcroft, 2002; Tang et al., 2005). In addition, because group I mGluRs have been implicated in various forms of synaptic plasticity (Balschun et al., 1999; Andjus et al., 2005; Grueter et al., 2006; Jung et al., 2006), modulation of A-type currents by group I mGluRs may represent a strategy shared among different types of neurons to adjust their output and might offer a potential mechanism for the effects of group I mGluRs on other types of plasticity such as learning and memory or drug addiction.

We further refined our understanding of these molecular events by determining the relative contribution of each group I mGluR subtype: mGlu1 and mGlu5. Our electrophysiology data 
A.
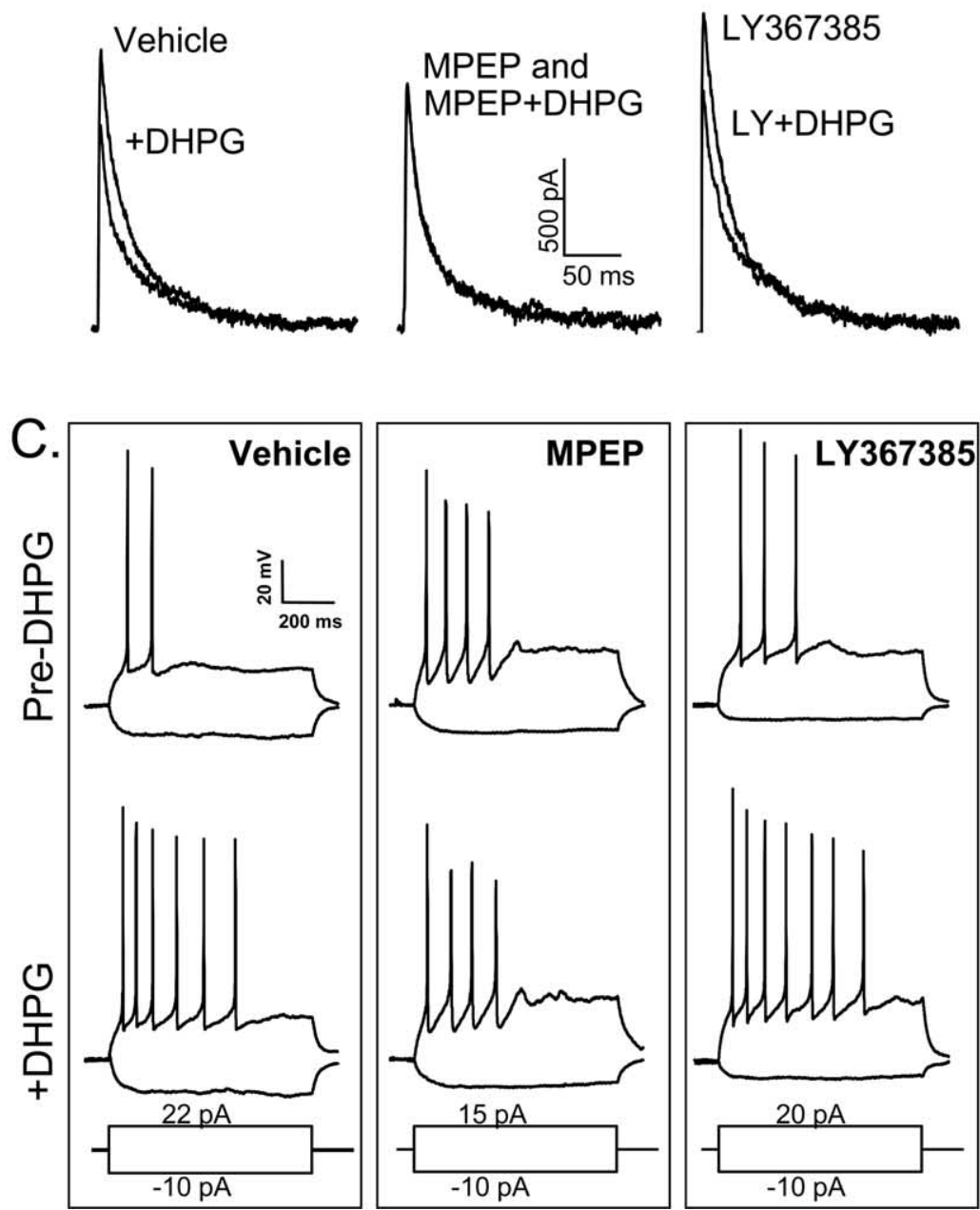

B.

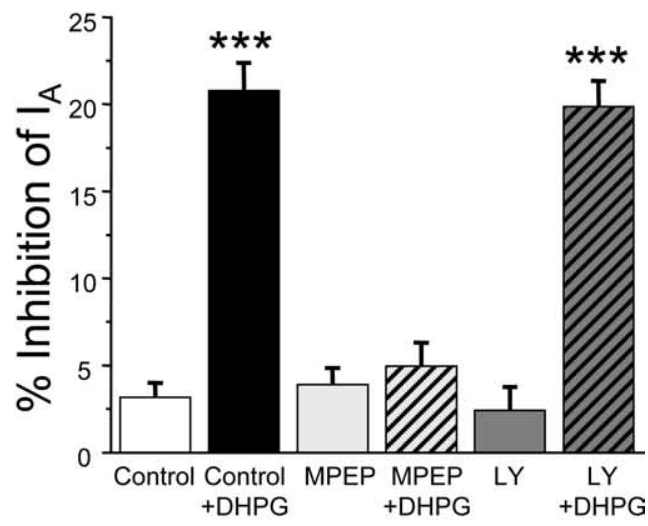

D.
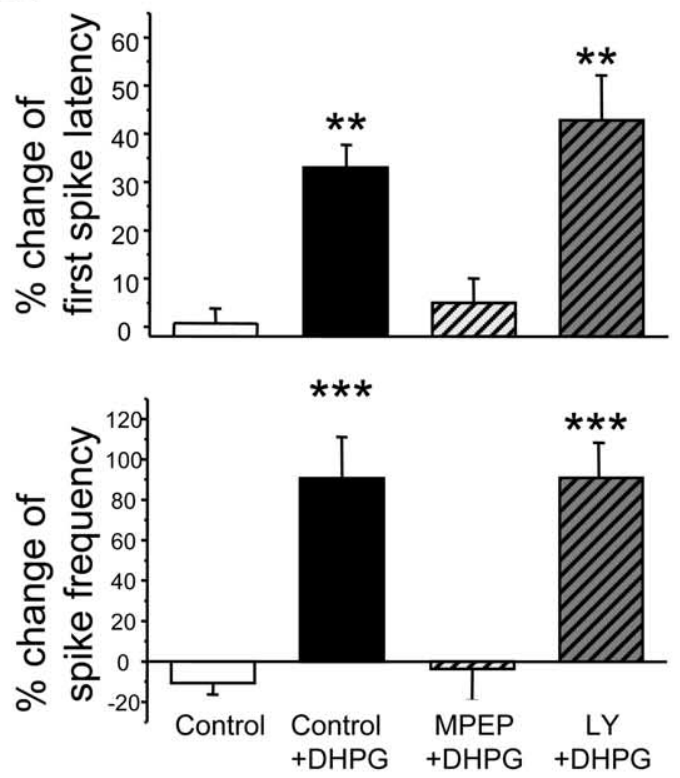

Figure 6. mGlu5 mediates DHPG-induced modulation of A-type currents and neuronal excitability in dorsal horn neurons. $A$, Representative traces of A-type currents recorded before and after application of $100 \mu \mathrm{m}$ DHPG in the presence of vehicle, $5 \mu \mathrm{m}$ MPEP, or $50 \mu \mathrm{m}$ LY367385 (LY). $\boldsymbol{B}$, Summary of effects of MPEP or LY367385 alone or the effects of DHPG in the presence of vehicle, MPEP, or LY367385 on peak amplitude of A-type currents. Values represent mean \pm SEM; $n=8$ neurons each; ${ }^{* * *} p<0.001$, one-way ANOVA followed by Dunnett's post hoc test to compare with the vehicle group (Control). C, Representative traces of action potentials recorded before and after application of $100 \mu \mathrm{M}$ DHPG in the presence of vehicle, $5 \mu \mathrm{M}$ MPEP, or $50 \mu \mathrm{M}$ LY367385 (LY). $D$, Summary of percentage of changes in first spike latency and spike frequency induced by DHPG in cultured dorsal horn neurons in the presence of vehicle, MPEP, and LY367385. Values represent mean \pm SEM; $n=8-10$ neurons each. ${ }^{* *} p<0.01 ;{ }^{* * *} p<0.001$, one-way ANOVA followed by Dunnett's post hoc test to compare with vehicle group.

showed that blockade of mGlu5, but not mGlu1, in the superficial dorsal horn completely abolished the modulation of A-type currents and neuronal excitability that we observe when we activate group I mGluRs with DHPG. Despite this, many behavioral studies have demonstrated a functional role of mGlul activation in various pain models (Neugebauer et al., 1999; Karim et al., 2001; Varney and Gereau, 2002). From the present study, we can conclude that mGlu5, but not mGlu1, modulates A-type currents in superficial dorsal horn neurons. The molecular mechanism underlying the contribution of mGlul to nociceptive behavior remains an outstanding question.

Three ERK phosphorylation sites have been identified previously in the C-terminal cytoplasmic domain of Kv4.2 (Adams et al., 2000). In the present study, ERK-induced phosphorylation of Kv4.2 at S616, but not T602 or T607, decreased A-type currents in superficial dorsal horn neurons after the activation of group I mGluRs. These results are consistent with our previous findings, when we activated ERK in dorsal horn neurons via PKC ( $\mathrm{Hu}$ et al., 2006). However, a previous study in oocytes suggests that phosphorylation of Kv4.2 at T607 decreases A-type currents and phosphorylation at S616 increases A-type currents (Schrader et al., 2006). In these experiments, Schrader et al. mimicked phosphorylation of T607 or S616 by mutating these sites to an aspartate, whereas in our experiments, we mutated T607 or S616 to an alanine to prevent endogenous phosphorylation of the channel. It is possible that the mutations used by Schrader et al. to mimic phosphorylation caused structural changes that affected the Kv4.2-mediated A-type currents differently than endogenous phosphorylation. Because we recorded from primary dorsal horn neurons, in which Kv4.2 is endogenously expressed, and Schrader et al. recorded from a heterologous Xenopus oocyte system, in which Kv4.2 is not endogenously expressed, it is also possible that the differences between our studies are attributable to differences in the expression of accessory proteins that affect the biophysical properties of Kv4.2 in neurons and oocytes.

Previous work in our laboratory has demonstrated that Kv4.2containing channels are primarily responsible for A-type potassium currents found in superficial dorsal horn neurons and these currents are critical modulators of excitability (Hu et al., 2006). Moreover, Kv4.2 was found to be necessary for ERK-dependent 

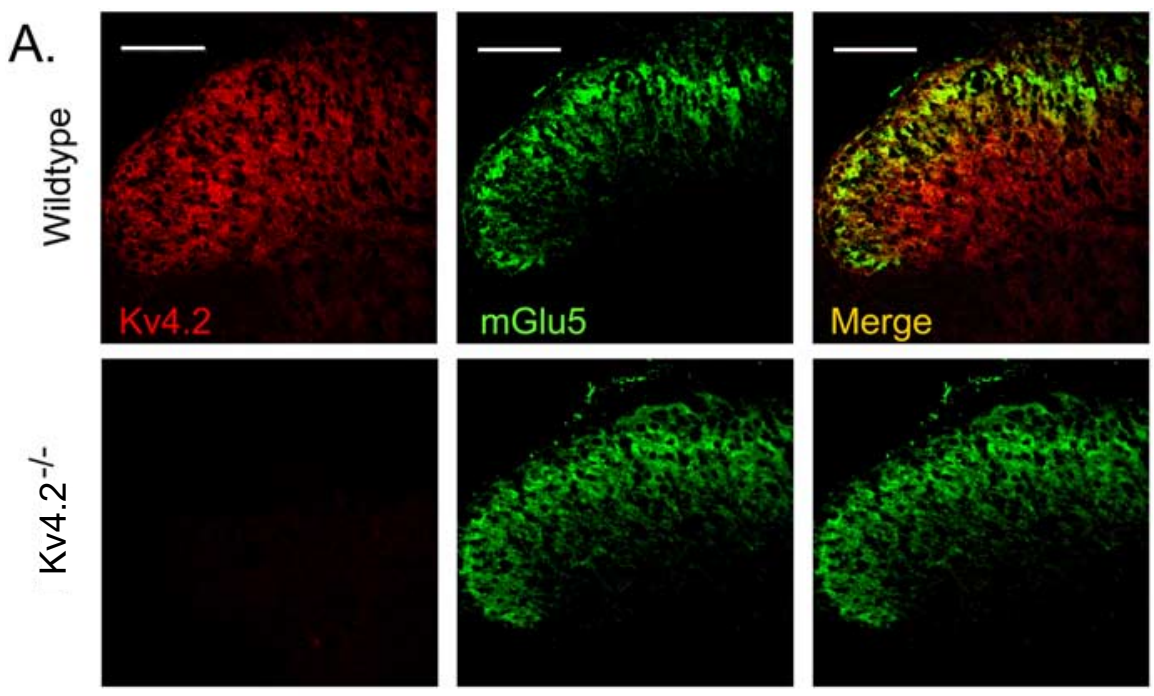

B.
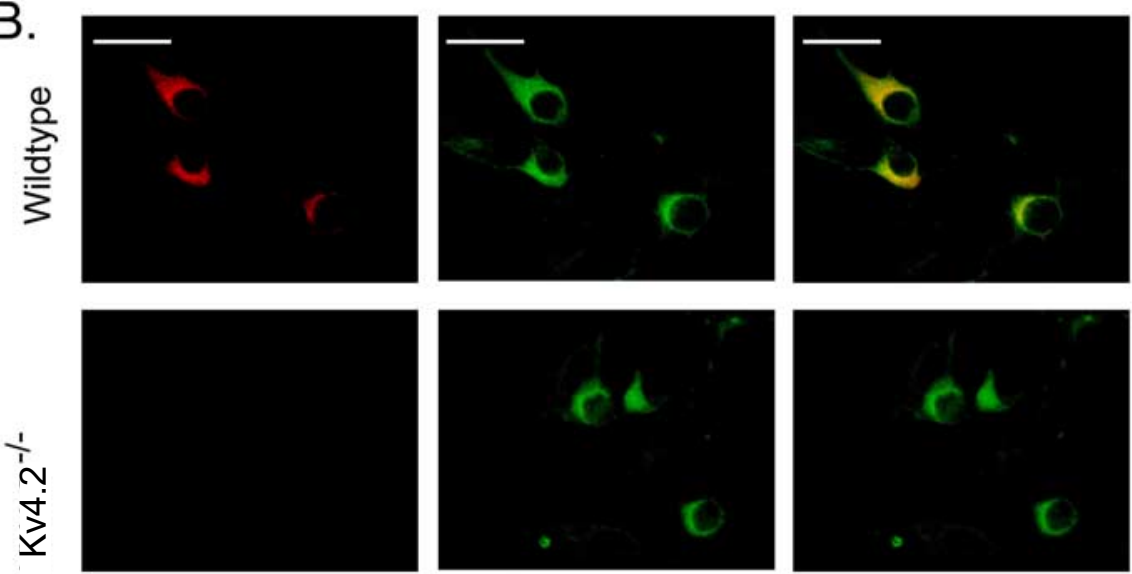

Figure 7. Colocalization of Kv4.2 subunit and mGlu5 in the mouse dorsal horn. $\boldsymbol{A}, \boldsymbol{B}$, Representative confocal images of Kv4.2 (red) and mGlu5 (green) coimmunofluorescent staining in the mouse dorsal horn (A) or cultured dorsal horn neurons (B). Merge of Kv4.2 and mGlu5 is shown in yellow. Scale bars: $\boldsymbol{A}, 200 \mu \mathrm{m} ; \boldsymbol{B}, 40 \mu \mathrm{m}$.
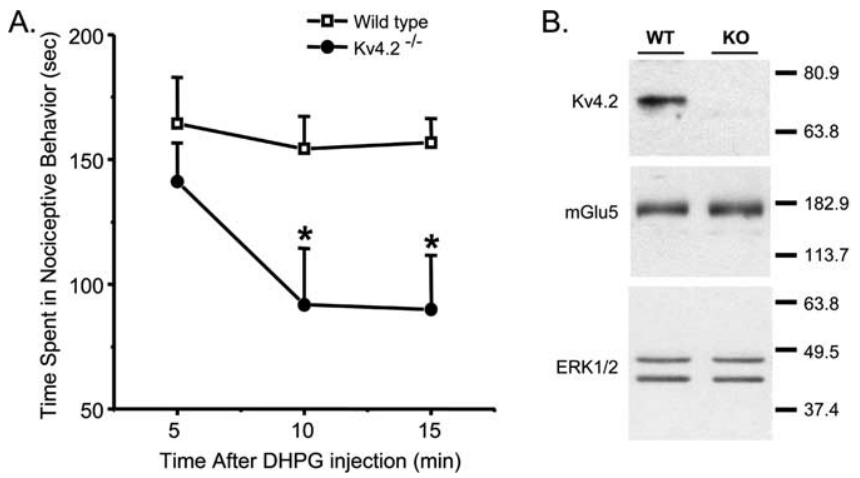

Figure 8. Spontaneous nociceptive behavior induced by intrathecal DHPG is impaired in Kv4.2 knock-out mice. $\boldsymbol{A}$, Time course of DHPG-induced spontaneous nociceptive behavior in wild-type or Kv4.2 $2^{-1-}$ littermate mice. Values represent mean \pm SEM; $n=13-18$ mice each; ${ }^{*} p<0.05$, one-way ANOVA with Bonferroni's correction. $\boldsymbol{B}$, Immunoblot of Kv4.2, mGlu5, and ERK in spinal cord samples from wild-type (WT) or Kv4.2 $2^{-/-}$. The position of molecular weight markers is indicated. K0, Knock-out.

modulation of A-type currents and excitability. In the present study, we extend these findings by demonstrating that Kv4.2 is also necessary for group I mGluR modulation of both A-type currents and excitability. The fact that DHPG has no effect on
A-type currents or excitability of dorsal horn neurons from $\mathrm{Kv} 4.2^{-/-}$mice likely represents the occlusion of a role normally played by ERK. Thus, in $K v 4.2^{-/-}$mice, the reduced A-type currents attributable to loss of the Kv4.2 protein leads to enhanced excitability of dorsal horn neurons. Because Kv4.2 is the target of mGlu5activated ERK in these cells and ERK reduces Kv4.2-mediated currents, the dorsal horn neurons are not made more hyperexcitable when DHPG is applied to the Kv4.2 $2^{-/-}$neurons.

In this study, we found that Kv4.2 expression is also necessary for group I mGluR-mediated nociceptive behavior. Thus, mice lacking functional Kv4.2 subunits show less nociceptive behavior after intrathecal injection of a group I mGluR agonist than their wild-type littermates. This effect is not attributable to compensatory changes in the expression of mGlu 5 or ERK in $K v 4.2^{-1-}$ mice because levels of these proteins are equivalent between $\mathrm{Kv} 4.2^{-/-}$and wildtype littermates. Interestingly, at $5 \mathrm{~min}$, which is the earliest time point that we evaluated after the intrathecal injection of the group I mGluR agonist DHPG, we did not observe a difference between $K v 4.2^{-/-}$and wild-type mice. This delay is likely not attributable to a delay in the action of DHPG after the intrathecal injection because previous studies from our laboratory have shown that ERK is activated 5 min after DHPG injection and that pretreatment with group I mGluRs antagonists reduces DHPGinduced nociceptive behavior at this time point (Karim et al., 2001). At the same time, unpublished observations from our laboratory suggest that blocking ERK does not affect DHPG-induced nociceptive behavior at this time point (H. Adwanikar, F. Karim, and R. W. Gereau, unpublished observations). A possible interpretation of these data are that, although ERK is activated by DHPG at earlier time points, its effect on downstream effectors such as Kv4.2 takes slightly longer to occur. Interestingly, activation of group I mGluRs in the dorsal horn has been shown to be involved in acute nociception, a process that is independent of ERK activation (Karim et al., 2001). Altogether, these results suggest that the initial effect of spinal group I mGluRs activation likely involves a different signaling pathway that is independent of ERK activation and Kv4.2. One possibility is that activation of group I mGluRs elevates cytosolic $\mathrm{Ca}^{2+}$ (Heinke and Sandkuhler, 2007), which may activate $\mathrm{Ca}^{2+}$-sensitive enzymes such as calcium/calmodulin-dependent kinase IV or adenylyl cyclases to regulate acute pain transmission (Mizuno and Giese, 2005).

The electrophysiological data presented in this paper support the model that mGlu5 activates ERK, which then phosphorylates $\mathrm{Kv} 4.2$, causing a decrease in A-type current and an increase in neuronal excitability. These signaling events could occur within the same neuron or it is also possible that the effects of group I 
mGluRs are actually presynaptic and that there are other extracellular signals and receptors involved in the postsynaptic activation of ERK and the subsequent modulation of Kv4.2. We have shown previously that mGlu5 is coexpressed with pERK in the dorsal horn after formalin-induced inflammation (Karim et al., 2001). Therefore, the phosphorylation of ERK by activation of mGlu5 likely occurs within the same neuron. In the present study, we show that Kv4.2 is coexpressed with mGlu5 and that the mGlu1/5 agonist DHPG increases pERK in Kv4.2-expressing dorsal horn neurons. These results extend our model and suggest that these three signaling events occur within the same neuron. Our findings are also consistent with previous reports that have shown that mGlu5, ERK, and Kv4.2 are expressed in the superficial dorsal horn (Karim et al., 2001; Huang et al., 2005; Hu et al., 2006).

In summary, this study sought to determine the molecular mechanism of group I mGluR effects on central sensitization and nociceptive behaviors. We discovered that the activation of mGlu5 reduces Kv4.2-mediated A-type currents and increases neuronal excitability in the spinal cord dorsal horn via ERK activation in vitro and that nociceptive behaviors caused by activating spinal group I mGluRs require Kv4.2 expression in vivo. These findings advance our understanding of the mechanisms underlying the role of mGlu 5 in pain processing and further identify a cell-surface receptor that is coupled to Kv4.2.

\section{References}

Adams JP, Anderson AE, Varga AW, Dineley KT, Cook RG, Pfaffinger PJ, Sweatt JD (2000) The A-type potassium channel Kv4.2 is a substrate for the mitogen-activated protein kinase ERK. J Neurochem 75:2277-2287.

Adwanikar H, Karim F, Gereau IV RW (2004) Inflammation persistently enhances nocifensive behaviors mediated by spinal group I mGluRs through sustained ERK activation. Pain 111:125-135.

Andjus PR, Bajic A, Zhu L, Strata P (2005) Metabotropic glutamate receptor-mediated currents at the climbing fiber to Purkinje cell synapse. J Chem Inf Model 45:1536-1538.

Balschun D, Manahan-Vaughan D, Wagner T, Behnisch T, Reymann KG, Wetzel W (1999) A specific role for group I mGluRs in hippocampal LTP and hippocampus-dependent spatial learning. Learn Mem 6:138-152.

Burdakov D, Ashcroft FM (2002) Cholecystokinin tunes firing of an electrically distinct subset of arcuate nucleus neurons by activating A-type potassium channels. J Neurosci 22:6380-6387.

Chen Y, Bacon G, Sher E, Clark BP, Kallman MJ, Wright RA, Johnson BG, Schoepp DD, Kingston AE (2000) Evaluation of the activity of a novel metabotropic glutamate receptor antagonist $(+/-)$-2-amino-2-(3-cis and trans-carboxycyclobutyl-3-(9-thioxanthyl)propionic acid) in the in vitro neonatal spinal cord and in an in vivo pain model. Neuroscience 95:787-793.

Fisher K, Coderre TJ (1996a) The contribution of metabotropic glutamate receptors (mGluRs) to formalin-induced nociception. Pain 68:255-263.

Fisher K, Coderre TJ (1996b) Comparison of nociceptive effects produced by intrathecal administration of mGluR agonists. NeuroReport 7:2743-2747

Fisher K, Coderre TJ (1998) Hyperalgesia and allodynia induced by intrathecal (RS)-dihydroxyphenylglycine in rats. NeuroReport 9:1169-1172.

Fisher K, Lefebvre C, Coderre TJ (2002) Antinociceptive effects following intrathecal pretreatment with selective metabotropic glutamate receptor compounds in a rat model of neuropathic pain. Pharmacol Biochem Behav 73:411-418.

Grueter BA, Gosnell HB, Olsen CM, Schramm-Sapyta NL, Nekrasova T, Landreth GE, Winder DG (2006) Extracellular-signal regulated kinase 1-dependent metabotropic glutamate receptor 5-induced long-term depression in the bed nucleus of the stria terminalis is disrupted by cocaine administration. J Neurosci 26:3210-3219.
Heinke B, Sandkuhler J (2007) Group I metabotropic glutamate receptorinduced $\mathrm{Ca}^{2+}$-gradients in rat superficial spinal dorsal horn neurons. Neuropharmacology 52:1015-1023.

Hu HJ, Gereau IV RW (2003) ERK integrates PKA and PKC signaling in superficial dorsal horn neurons. II. Modulation of neuronal excitability. J Neurophysiol 90:1680-1688.

Hu HJ, Bhave G, Gereau IV RW (2002) Prostaglandin and protein kinase A-dependent modulation of vanilloid receptor function by metabotropic glutamate receptor 5: potential mechanism for thermal hyperalgesia. J Neurosci 22:7444-7452.

Hu HJ, Glauner KS, Gereau IV RW (2003) ERK integrates PKA and PKC signaling in superficial dorsal horn neurons. I. Modulation of A-type $\mathrm{K}^{+}$ currents. J Neurophysiol 90:1671-1679.

Hu HJ, Carrasquillo Y, Karim F, Jung WE, Nerbonne JM, Schwarz TL, Gereau IV RW (2006) The kv4.2 potassium channel subunit is required for pain plasticity. Neuron 50:89-100.

Huang HY, Cheng JK, Shih YH, Chen PH, Wang CL, Tsaur ML (2005) Expression of A-type K channel alpha subunits Kv 4.2 and Kv 4.3 in rat spinal lamina II excitatory interneurons and colocalization with painmodulating molecules. Eur J Neurosci 22:1149-1157.

Jerng HH, Pfaffinger PJ, Covarrubias M (2004) Molecular physiology and modulation of somatodendritic A-type potassium channels. Mol Cell Neurosci 27:343-369.

Ji RR, Woolf CJ (2001) Neuronal plasticity and signal transduction in nociceptive neurons: implications for the initiation and maintenance of pathological pain. Neurobiol Dis 8:1-10

Ji RR, Kohno T, Moore KA, Woolf CJ (2003) Central sensitization and LTP: do pain and memory share similar mechanisms? Trends Neurosci 26:696-705.

Jung SJ, Kim SJ, Park YK, Oh SB, Cho K, Kim J (2006) Group I mGluR regulates the polarity of spike-timing dependent plasticity in substantia gelatinosa neurons. Biochem Biophys Res Commun 347:509-516.

Karim F, Wang CC, Gereau IV RW (2001) Metabotropic glutamate receptor subtypes 1 and 5 are activators of extracellular signal-regulated kinase signaling required for inflammatory pain in mice. J Neurosci 21:3771-3779.

Kawasaki Y, Kohno T, Zhuang ZY, Brenner GJ, Wang H, Van Der Meer C, Befort K, Woolf CJ, Ji RR (2004) Ionotropic and metabotropic receptors, protein kinase A, protein kinase $\mathrm{C}$, and Src contribute to C-fiberinduced ERK activation and cAMP response element-binding protein phosphorylation in dorsal horn neurons, leading to central sensitization. J Neurosci 24:8310-8321.

Mannaioni G, Marino MJ, Valenti O, Traynelis SF, Conn PJ (2001) Metabotropic glutamate receptors 1 and 5 differentially regulate CA1 pyramidal cell function. J Neurosci 21:5925-5934.

Mizuno K, Giese KP (2005) Hippocampus-dependent memory formation: do memory type-specific mechanisms exist? J Pharmacol Sci 98:191-197.

Neugebauer V, Chen PS, Willis WD (1999) Role of metabotropic glutamate receptor subtype mGluR1 in brief nociception and central sensitization of primate STT cells. J Neurophysiol 82:272-282.

Obata K, Noguchi K (2004) MAPK activation in nociceptive neurons and pain hypersensitivity. Life Sci 74:2643-2653.

Schrader LA, Birnbaum SG, Nadin BM, Ren Y, Bui D, Anderson AE, Sweatt JD (2006) ERK/MAPK regulates the Kv4.2 potassium channel by direct phosphorylation of the pore-forming subunit. Am J Physiol Cell Physiol 290:C852-C861.

Shibata R, Nakahira K, Shibasaki K, Wakazono Y, Imoto K, Ikenaka K (2000) A-type $\mathrm{K}^{+}$current mediated by the $\mathrm{Kv} 4$ channel regulates the generation of action potential in developing cerebellar granule cells. J Neurosci 20:4145-4155.

Sluka KA, Audette KM (2006) Activation of protein kinase C in the spinal cord produces mechanical hyperalgesia by activating glutamate receptors, but does not mediate chronic muscle-induced hyperalgesia. Mol Pain 2:13.

Starodub AM, Wood JD (2000) Histamine suppresses A-type potassium current in myenteric neurons from guinea pig small intestine. J Pharmacol Exp Ther 294:555-561.

Takahashi T, Berger AJ (1990) Direct excitation of rat spinal motoneurones by serotonin. J Physiol (Lond) 423:63-76.

Tang SL, Tran V, Wagner EJ (2005) Sex differences in the cannabinoid modulation of an A-type $\mathrm{K}^{+}$current in neurons of the mammalian hypothalamus. J Neurophysiol 94:2983-2986. 
Topolnik L, Azzi M, Morin F, Kougioumoutzakis A, Lacaille JC (2006) mGluR1/5 subtype-specific calcium signalling and induction of longterm potentiation in rat hippocampal oriens/alveus interneurones. J Physiol (Lond) 575:115-131.

Varga AW, Yuan LL, Anderson AE, Schrader LA, Wu GY, Gatchel JR, Johnston D, Sweatt JD (2004) Calcium-calmodulin-dependent kinase II modulates Kv4.2 channel expression and upregulates neuronal A-type potassium currents. J Neurosci 24:3643-3654.

Varney MA, Gereau IV RW (2002) Metabotropic glutamate receptor involvement in models of acute and persistent pain: prospects for the development of novel analgesics. Curr Drug Targets CNS Neurol Disord $1: 283-296$.

Vydyanathan A, Wu ZZ, Chen SR, Pan HL (2005) A-type voltage-gated $\mathrm{K}^{+}$ currents influence firing properties of isolectin B4-positive but not isolectin B4-negative primary sensory neurons. J Neurophysiol 93:3401-3409.

Wang D, Sumners C, Posner P, Gelband CH (1997) A-type K ${ }^{+}$current in neurons cultured from neonatal rat hypothalamus and brain stem: modulation by angiotensin II. J Neurophysiol 78:1021-1029.

Young MR, Fleetwood-Walker SM, Dickinson T, Blackburn-Munro G, Sparrow H, Birch PJ, Bountra C (1997) Behavioural and electrophysiological evidence supporting a role for group I metabotropic glutamate receptors in the mediation of nociceptive inputs to the rat spinal cord. Brain Res 777:161-169.

Yuan LL, Adams JP, Swank M, Sweatt JD, Johnston D (2002) Protein kinase modulation of dendritic $\mathrm{K}^{+}$channels in hippocampus involves a mitogen-activated protein kinase pathway. J Neurosci 22:4860-4868. 